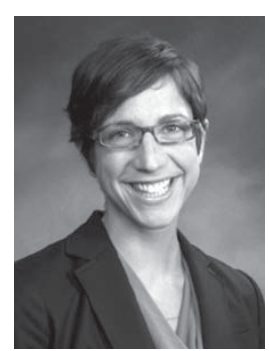

Alyssa Shell, a 2014 Pisacano

Scholar, is at the University of Texas Medical Branch (UTMB) earning her $\mathrm{MD} / \mathrm{PhD}$ in Population Health Sciences. Alyssa graduated with honors with a Bachelor of Arts in Social Studies from Harvard University. She also received a Certificate in Health Policy.

While in medical school, Alyssa received the John P. McGovern Student Award in Oslerian Medicine and is a member of the Gold Humanism Honor Society. In 2012, she received the United States Public Health Services Excellence in Public Health Award. Alyssa volunteered for 3 years and then served as the Director of St. Vincent's Student Clinic at UTMB.

Alyssa has a patient-centered attitude that started in high school during a summer volunteer program in Kenya where she taught classes on HIV education. Her career goals include practicing full-spectrum family medicine, working to alleviate health care disparities, especially in rural areas, and to eventually become a leader in health care policy.

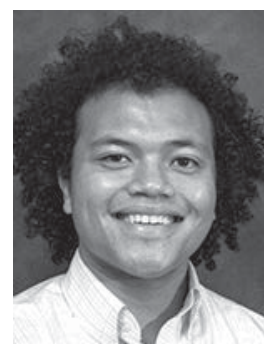

Nicholas Kenji Taylor, a 2014 Pisacano Scholar, is at the Perelman School of Medicine at University of Pennsylvania. He graduated magna cum laude and Phi Beta Kappa from Brown University earning degrees in East Asian Studies and Neuroscience. He also completed a Master in Innovation

Management and Entrepreneurship Engineering at Brown.

In medical school, Kenji managed The Cut Hypertension Program in which medical students visit African American barbershops to perform blood pressure screenings and educate customers. He continued throughout medical school to build this program via an Albert Schweitzer Fellowship and United Health Foundation award. Kenji had the opportunity to work with a program in South Africa to build a system that followed mothers infected with HIV through the process of preventing HIV transmission to their infants. Kenji recently completed an epidemiology fellowship in Namibia and Malawi.

Kenji envisions his future in family medicine as the privilege to provide one-on-one primary care to individuals in his local community as well as strengthen systems of health and preventative services to the most vulnerable populations around the world.

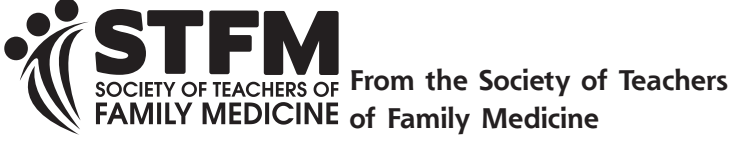

Ann Fam Med 2014;12:581-582. doi: 10.1370/afm.1729.

\section{STFM OFFERS OPPORTUNITIES FOR SCHOLARLY ACTIVITY}

New requirements by the Accreditation Council for Graduate Medical Education (ACGME) and the Liaison Committee on Medical Education (LCME) underscore the importance of clinical inquiry and scholarship in medical education:

- "The faculty of a medical school demonstrate a commitment to continuing scholarly productivity that is characteristic of an institution of higher learning." ${ }^{\prime \prime}$ - LCME

- "A medical education program is conducted in an environment that fosters the intellectual challenge and spirit of inquiry appropriate to a community of scholars and provides sufficient opportunities, encouragement, and support for medical student participation in research and other scholarly activities of its faculty."1-LCME

- "The faculty must establish and maintain an environment of inquiry and scholarship with an active research component."2_-ACGME

- "The sponsoring institution and program should allocate adequate educational resources to facilitate resident involvement in scholarly activities."2-ACGME

ACGME defines scholarly activity as work that contributes to knowledge available to the discipline of family medicine and/or its subspecialty fellowship areas. The knowledge must be shared with peers and subject to peer review. Faculty members must document 2 scholarly activities every 5 years; residents must document 1 by the end of their residency. ${ }^{3}$

STFM has ramped up opportunities for the academic family medicine community to advance scholarship through the following initiatives:

Family Medicine-Submissions continue to rise for STFM's flagship journal, which has been sharing educational research for more than 30 years. Recent changes include full text, online searchable journals. Additional pages have also been added to the journal, allowing for the publication of approximately 1 more Original Article per issue.

Annals of Family Medicine-STFM is the third largest financial contributor to this peer-reviewed research 
journal for scientists, clinicians, policy makers, and the patients and communities they serve. The journal is dedicated to advancing knowledge essential to understanding and improving health and primary care.

\section{CAFM Educational Research Alliance (CERA) -} CERA was developed specifically to increase the quality and frequency of research and scholarly activity among members of CAFM organizations. It has done exactly that. Since the initiative launched in late 2011, the research has been disseminated through 16 peer-reviewed papers and 30 presentations. The data are available for secondary research by CAFM organizations.

STFM Conferences-The Annual Spring Conference, Conference on Medical Student Education, and Conference on Practice Improvement offer hundreds of opportunities for the sharing of scholarly work by faculty, fellows, residents, and students.

Residency Accreditation Toolkit-This new online resource provides the background, tools, and training to help residency programs meet the requirements of the ACGME's Next Accreditation System. The toolkit has a section on scholarly activity that includes tips on how to get started and a list of sample scholarly activities.

STFM Resource Library (fmdrl.org)_LLok for enhancements to this widely used repository in 2015, including expanded opportunities for scholarship.

\section{Family Medicine Residency Curriculum Resource-} The Association of Family Medicine Residency Directors and STFM are in the midst of a multiyear collaborative to build an online repository of competencybased curriculum, organized by postgraduate year. Submitted curriculum is peer reviewed, which means it meets the guidelines for scholarly activity. Submissions are still being accepted.

Grant Generating Project-STFM is 1 of 3 financial partners in the Grant Generating Project, a fellowship that equips family medicine researchers with the skills they need to successfully develop and submit grants for research funding.

Within the strategies of the Family Medicine for America's Health Initiative is the expectation that family medicine will continuously improve the health and quality of care of patients. This can only be achieved by consistently integrating new knowledge into clinical practice and teaching. Creating and nurturing an environment of inquiry and scholarship in medical schools and residency programs ultimately benefits faculty, learners, and patients.

$$
\begin{array}{r}
\text { Mary Theobald, MBA } \\
\text { Vice President, Communications and Programs } \\
\text { Society of Teachers of Family Medicine }
\end{array}
$$

\section{References}

1. Liaison Committee on Medical Education. Functions and structure of a medical school. Washington, DC: Liaison Committee on Medical Education, March 2014

2. Accreditation Council for Graduate Medical Education. ACGME Program Requirements for Graduate Medical Education in Family Medicine. Chicago: Accreditation Council for Graduate Medical Education, September 2013.

3. ACGME Review Committee for Family Medicine. Scholarly Activity Guidelines. Chicago: Accreditation Council for Graduate Medical Education, 2012.

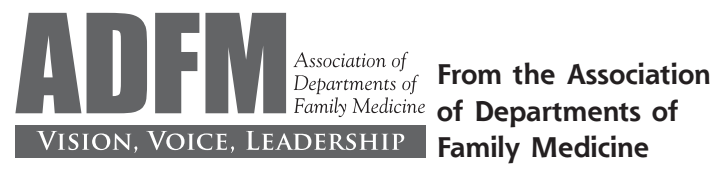

Ann Fam Med 2014;12:582-583. doi: 10.1370/afm.1716.

\section{ELECTRONIC HEALTH RECORDS: HOW WILL STUDENTS LEARN IF THEY CAN'T PRACTICE?}

Electronic health records (EHR) are becoming ubiquitous, with $78 \%$ of office-based physicians reporting use of an EHR in 2013. ${ }^{1}$ EHR systems have the potential to enhance quality and safety, but there is a risk that medical students are entering residencies without adequate preparation to fully and effectively use this important instrument. Future physicians must learn skills to enhance relationships while using the EHR in modern clinical practices, avoiding barriers such as 'continuous partial attention' and minimizing the patient in favor of the 'third person in the room.' ${ }^{2-6}$ Learning how to elicit medical histories while electronically recording key findings, using EHRassociated decision-making tools and providing management plans requires full EHR access. ${ }^{5}$ Using the registry and analytic functions of EHRs is important for developing skills in population health management. Future physicians must also become familiar with safety reminders and point of care references to provide efficient and effective care. Unfortunately, students at many medical schools are not able to adequately access EHRs to receive this necessary training.

Surveys regarding student use of $\mathrm{EHR}^{7,8}$ show broad institutional variation. Most differences are the 